\title{
Effect of cachexia on bone turnover in cancer patients: a case-control study
}

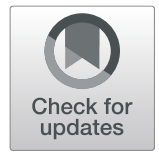

Hannes Zwickl', Elisabeth Zwickl-Traxler ${ }^{1,2}$, Alexander Haushofer ${ }^{3}$, Josef Seier $^{3}$, Klaus Podar $^{1,2}$, Michael Weber $^{1}$, Klaus Hackner ${ }^{1,4}$, Nico Jacobi ${ }^{5}$, Martin Pecherstorfer ${ }^{1,2}$ and Sonia Vallet ${ }^{1,2^{*}}$

\begin{abstract}
Background: Increased bone turnover is frequently observed in advanced cancer and predominantly related to bone metastases or therapy. Cachexia represents an important cause of morbidity and mortality in cancer patients. Key features are weight loss, muscle wasting and chronic inflammation, which induce profound metabolic changes in several organs, including the bone. However, whether cachexia contributes to abnormal bone metabolism in cancer patients is unknown. Aim of the present study was to determine the potential correlation of bone turnover markers with body composition and laboratory parameters in treatment-naïve cancer patients.
\end{abstract}

Methods: In this cross-sectional study we measured the levels of carboxy terminal telopeptide of collagen (CTX), an indicator of bone resorption, as well as osteocalcin (Ocn) and procollagen type I N-terminal propeptide (PINP), indicators of bone formation, in 52 cancer patients and correlated with body composition and laboratory parameters. Univariate and multivariate logistic analysis were performed to identify determinants of negative bone remodeling balance, estimated by CTX/Ocn and CTX/PINP ratio.

Results: Based on weight loss, body mass index and muscle mass, patients were divided into a cachectic (59.6\%) and a control (40.4\%) group. After correcting for the presence of bone metastases, our results showed a significant upregulation of CTX in cachectic patients compared to non-cachectic cancer patients (median $0.38 \mathrm{vs} 0.27 \mathrm{ng} / \mathrm{mL}$, $p<0.05$ ), with no difference in Ocn and PINP levels (mean $14 \mathrm{vs.} 16 \mathrm{ng} / \mathrm{ml}, p=0.2$ and median $32 \mathrm{vs} .26 \mu \mathrm{g} / \mathrm{L}, p=$ 0.5 , respectively). In addition, the CTX/Ocn and the CTX/PINP ratio were indicative of bone resorption in $68 \%$ and $60 \%$ of cachexia patients, respectively (vs. $20 \%$ and $31 \%$ in the control group, $p=0.002$ and $p=0.06$ ). The main determinants of the unbalanced bone turnover were hypoalbuminemia for the CTX/Ocn ratio (OR 19.8, $p<0.01$ ) and high CRP for the CTX/PINP ratio (OR 5.3, $p<0.01)$ in the multivariate regression analysis.

Conclusions: CTX is substantially higher in cachectic patients compared to non-cachectic oncological patients and hypoalbuminemia as well as elevated CRP concentrations are independent predictors of a negative bone remodeling balance in cancer patients. These results strongly indicate that cachexia correlates with exacerbated bone turnover in cancer.

Keywords: Cachexia, Bone turnover, Carboxy terminal telopeptide of collagen type I (CTX), Osteocalcin (Ocn), Procollagen type I N-terminal propeptide (PINP), Hypoalbuminemia, CRP

\footnotetext{
* Correspondence: sonia.vallet@krems.lknoe.at

'Karl Landsteiner University of Health Sciences, Dr. Karl-Dorrek-Strasse 30, Krems 3500, Austria

${ }^{2}$ Department of Internal Medicine 2, University Hospital Krems, Mitterweg 10, Krems 3500, Austria

Full list of author information is available at the end of the article
}

(C) The Author(s). 2021 Open Access This article is licensed under a Creative Commons Attribution 4.0 International License, which permits use, sharing, adaptation, distribution and reproduction in any medium or format, as long as you give appropriate credit to the original author(s) and the source, provide a link to the Creative Commons licence, and indicate if changes were made. The images or other third party material in this article are included in the article's Creative Commons licence, unless indicated otherwise in a credit line to the material. If material is not included in the article's Creative Commons licence and your intended use is not permitted by statutory regulation or exceeds the permitted use, you will need to obtain permission directly from the copyright holder. To view a copy of this licence, visit http://creativecommons.org/licenses/by/4.0/ The Creative Commons Public Domain Dedication waiver (http://creativecommons.org/publicdomain/zero/1.0/) applies to the data made available in this article, unless otherwise stated in a credit line to the data. 


\section{Background}

Cachexia is a multiorgan syndrome affecting up to $80 \%$ of patients with advanced cancer. Not only is it associated with a poor quality of life, but also with high mortality rates, ranging from 20 to $80 \%$ in the first year of diagnosis [1]. Hallmarks of cancer cachexia are loss of body weight, depletion of muscle mass (sarcopenia) and systemic inflammation [2]. As a result, several tissues and organs, including adipose tissue, liver, and bone, undergo metabolic changes, which in turn contribute to cachexia in a vicious cycle.

The bone is a metabolically active organ, which undergoes a continuous remodeling mediated by a balanced activity of bone-resorbing cells, osteoclasts, and boneforming cells, osteoblasts [3]. Changes in bone remodeling can be tracked by measuring serum levels of bone turnover markers (BTMs), including collagen breakdown products (e.g. carboxy terminal telopeptide of collagen type I (CTX)) and osteoclast-specific enzymes (e.g. acid phosphatase and cathepsin) for bone resorption; as well as by-products of collagen neosynthesis (e.g. procollagen type I N-terminal propeptide (PINP)) and osteoblastassociated proteins (e.g. bone-specific alkaline phosphatase and osteocalcin (Ocn)) for bone formation [4]. BTM serum levels strongly correlate with bone mineral density and predict risk of bone fractures $[5,6]$.

In cancer patients, bone damage results most frequently from skeletal metastatic disease, but is also a complication of anti-tumoral agents, hormone-targeted strategies in particular [7]. Importantly, osteopenia has also been documented in therapy-naïve patients without evidence of skeletal involvement [8,9]. Indeed, systemic inflammation, muscle wasting, and weight loss may contribute to bone mineral loss, as observed in patients with chronic heart failure or arthritis [1, 10]. The link between cancer cachexia and increased bone turnover is supported by findings in several preclinical models, but this data has not been as yet confirmed in the clinical setting $[11,12]$.

To elucidate the effect of cachexia on bone turnover in cancer patients, we conducted a cross-sectional study investigating BTMs and bone regulators in treatmentnaïve cancer patients with and without cachexia and their association with body composition analysis and laboratory parameters.

\section{Methods}

\section{Patient population}

The patient population was drawn from a recent study investigating metabolic alterations in cancer cachexia [13]. In brief, 60 adult patients with newly diagnosed cancer with or without cachexia (defined as unintentional weight loss of at least $5 \%$ during the last 6 months, or weight loss $>2 \%$ coupled with a body mass index
(BMI) of $<20 \mathrm{~kg} / \mathrm{m}^{2}$, or weight loss $>2 \%$ and sarcopenia [14]) were recruited at the University Hospital of Krems between February 2016 and June 2018. All patients were male and treatment-naïve to limit potential confounding factors [15]. Exclusion criteria were chronic cardiovascular diseases, insulin-dependent diabetes, or acute inflammatory state at the time of enrollment, as assessed per medical records. In addition, for the cross-sectional BTM analysis subjects with abnormal liver values due to hepatic metastases were excluded (bilirubin > $>1.5 \mathrm{x}$ upper limit of normal and/or GGT $>2 \mathrm{x}$ upper limit of normal, $n=8$ ).

Information on health and medical history was collected by interviewer questionnaires. All patients underwent clinical examination including blood pressure and anthropometric measurement (height, weight, and waist circumference), as well as routine laboratory parameters. BMI was calculated as weight in kilograms divided by height in meters squared and classified as normal (18.5$\left.24.9 \mathrm{~kg} / \mathrm{m}^{2}\right)$, overweight $\left(25-29.9 \mathrm{~kg} / \mathrm{m}^{2}\right)$, and obese (> $30 \mathrm{~kg} / \mathrm{m}^{2}$ ) according to the World Health Organization recommendations

All patients provided written informed consent. The study was approved by the Ethical Committee of Lower Austria and performed according to the Declaration of Helsinki (1996).

\section{Body composition measurements}

Analysis of body composition was performed with BodyExplorer (Juwell Medical GmbH; Rheine, Germany) following the manufacturer's instructions. Briefly, tetrapolar single frequency $(50 \mathrm{kHz})$ bioimpedance analysis (BIA) was conducted in supine patients. The following measurements were provided: I) the primary impedance parameters: resistance, reactance and phase angle, II) the algorithm-based parameters (calculated automatically by the BIA device): total body water, body cell mass (BCM), fat mass and the ratio of extracellular to intracellular water $(\mathrm{ECW} / \mathrm{ICW})$ [16]. In addition, skeletal muscle mass was estimated using the BIA equation of Janssen et al. [17]. Skeletal muscle index (SMI) was calculated by the ratio of skeletal muscle mass $(\mathrm{kg})$ to squared body height (meter) and sarcopenia was defined as SMI $<14.6$ $\mathrm{kg} / \mathrm{m}^{2}[14]$.

\section{Laboratory measurements}

Blood samples were collected between 8:00 and 10:00 a.m. after at least $12 \mathrm{~h}$ of fasting. Serum was separated immediately after phlebotomy and stored at $-80^{\circ} \mathrm{C}$ until analysis. Hemoglobin, lymphocytes, creatinine, Creactive protein (CRP), albumin, cholinesterase (CHE), transaminases, alkaline phosphatase (ALP), gamma glutamyl transferase (GGT), as well as bone-related parameters (CTX, Ocn, PINP, calcium $(\mathrm{Ca})$, phosphate, thyroid 
stimulating hormone (TSH), 25-hydroxy vitamin D $(25(\mathrm{OH}) \mathrm{D})$ and parathyroid hormone $(\mathrm{PTH}))$ were determined by well-validated laboratory routine methods. In particular, Ocn levels were assessed by a chemiluminescence immunoassay detecting intact Ocn (1-49) and large fragments (1-43). Calcium concentrations were corrected for serum albumin. The glomerular filtration rate (eGFR) was estimated using the MDRD formula.

To evaluate the balance of bone resorption and formation both the CTX/Ocn and the CTX/PINP ratio were calculated $[18,19]$ : values $>0.022$ and $>0.011$ (respective medians of the study population) indicate bone resorption.

Vitamin D status was defined as deficient for $25(\mathrm{OH}) \mathrm{D}$ concentrations $<25 \mathrm{ng} / \mathrm{mL}$ and as insufficient for $25-50$ $\mathrm{ng} / \mathrm{mL}[20]$.

Grouping of the variables hemoglobin, albumin, CRP and CHE was carried out using standard thresholds: hypoalbuminemia was defined as albumin $<35 \mathrm{~g} / \mathrm{L}$, high CRP as CRP $>1 \mathrm{mg} / \mathrm{dL}$, anemia as hemoglobin $<12,5 \mathrm{~g} /$ $\mathrm{dL}$, and low CHE as CHE < $5000 \mathrm{U} / \mathrm{L}[21,22]$.

\section{Statistical analysis}

Categorical variables are expressed as percentages, statistical comparisons were assessed with the Pearson's $x^{2}$ test. Continuous variables were tested for normal distribution using the Shapiro-Wilk test. For comparisons of means (normally distributed variables) the Student's ttest was used; for medians (not normally distributed variables) the Mann-Whitney $U$ test or, in case of 3 or more variables, the Kruskal-Wallis Test were used. Correlations between CTX, Ocn, PINP and anthropometric, BIA and laboratory parameters were assessed using Spearman rank correlation coefficients.

To identify factors associated with a negative bone remodeling balance (defined as CTX/Ocn $>0.022$ or CTX/ PINP >0.011), a binomial logistic regression analysis with backward stepwise approach was performed. All variables with $p$-values $<0.1$ in the univariate analysis were included in the logistic regression model. Odds ratio and $95 \%$ confidence interval were used as an estimate of the risk. The Hosmer-Lemeshow test was used to assess model adequacy. Multicollinearity was assessed with variance inflation factors to confirm independence of variables included in the regression model. All statistical analyses were performed using IBM SPSS Statistics for Windows v26 (IBM Corp., Armonk, NY, USA). A $p$ value of $<0.05$ was considered significant.

\section{Results}

\section{Patient characteristics}

A total of 52 male patients with cancer at first diagnosis were included in the cross-sectional BTM study. They were further classified as cachectic $(n=31)$ or not $(n=$
21) based on the international consensus criteria for cancer cachexia [14]. The most frequent tumor types were lung cancers (73\%) and gastrointestinal tumors (15\%).

Table 1 summarizes the clinical characteristics of the studied population. The average age at diagnosis was 64 years. The majority of the patients (69.2\%) presented with advanced stage disease (stage 3 or 4 ) and $15.4 \%$ had bone metastases with no statistical differences between the two groups. More than half of the patients (63.5\%) presented at first diagnosis as overweight or obese, which were mainly observed in the control group $(81 \%$ vs $51.6 \%$ of the patients in the cachexia group, $p=0.03$ ). The $9 \mathrm{~kg}$ difference in body weight between the two groups was caused by a $4 \mathrm{~kg}$ lower BCM ( 28 vs $31.5, p=$ 0.01 ), as well as a numerically, but not statistically significant lower fat mass and total body water in cachectic patients compared to controls. Sarcopenia was observed in less than $10 \%$ of the patients, with no significant difference between cachexia and control $(9.6 \%$ vs. 9.5\%, $p=0.99$ ). In contrast, phase angle, which is an indicator of nutritional status and muscle quality, was significantly lower in patients with cachexia (5.4 vs $6.3, p<0.01)[15$, 23].

In agreement with cachexia having been characterized by chronic inflammation [24], cachectic patients in our study presented with significantly higher CRP serum levels than in the non-cachectic control group (median 2 vs $0.6 \mathrm{mg} / \mathrm{dL}, p<0.01)$. Moreover, albumin (33.9 vs 39 $\mathrm{g} / \mathrm{L}, p<0.01)$ and CHE (5629 vs $7079 \mathrm{U} / \mathrm{L}, p<0.001)$, both indicators of hepatic function and nutritional status, were significantly reduced in cachectic patients. Interestingly, ALP serum levels were higher in patients with cachexia compared to the non-cachectic cancer control group (median 84 vs $68 \mathrm{U} / \mathrm{L}, p<0.05$ ), confirming recent reports of mild cholestasis in cancer cachexia [25]. Importantly, eGFR did not significantly differ between the two groups.

These observations highlight the specific clinical and laboratory features, which distinguish cachectic from non-cachectic cancer patients, including low BMI, anemia, hypoalbuminemia, and inflammation [26].

\section{Parameters of bone turnover and bone regulators}

To elucidate the effect of cachexia on bone metabolism of cancer patients, we analyzed the levels of BTMs, CTX for bone resorption, Ocn and PINP for bone formation in particular, as well as of regulators of bone metabolism (PTH, vitamin D and TSH) based on the presence or absence of skeletal metastases (Table 2). CTX was higher in patients with cachexia compared to the non-cachectic cancer control group, but the upregulation in the cancer cachexia group gained significance after exclusion of patients with bone metastases $(0.38 \mathrm{vs} 0.31 \mathrm{ng} / \mathrm{ml}, p=0.1$ 
Table 1 Patient characteristics

\begin{tabular}{|c|c|c|c|c|}
\hline & $\begin{array}{l}\text { All } \\
(n=52)\end{array}$ & Cancer Cachexia $(n=31)$ & $\begin{array}{l}\text { Cancer } \\
(n=21)\end{array}$ & $p$ \\
\hline Age $^{a}$ & $64.3( \pm 8.5)$ & $64.3( \pm 8.3)$ & $64.4( \pm 9.1)$ & 0.9 \\
\hline Stage III and IV, n (\%) & $36(69.2)$ & $22(71)$ & $14(67)$ & 0.7 \\
\hline Bone Metastases, n (\%) & $8(15.4)$ & $3(9.7)$ & $5(24)$ & 0.2 \\
\hline Tumor Type & & & & 0.1 \\
\hline Lung, $n(\%)$ & $38(73)$ & $19(61.2)$ & $19(90.4)$ & \\
\hline Gastrointestinal, n (\%) & $8(15.4)$ & $7(22.6)$ & $1(4.8)$ & \\
\hline Hematological, n (\%) & $3(5.8)$ & $3(9.7)$ & $0(0)$ & \\
\hline Other, n (\%) & $3(5.8)$ & $2(6.5)$ & $1(4 ., 8)$ & \\
\hline \multicolumn{5}{|l|}{ Anthropometric and BIA parameters } \\
\hline $\mathrm{BMI}, \mathrm{kg} / \mathrm{m}^{2} \mathrm{a}$ & $26.1( \pm 5.1)$ & $25.6( \pm 4.8)$ & $28( \pm 5.1)$ & 0.04 \\
\hline $\mathrm{BMI}>25 \mathrm{~kg} / \mathrm{m}^{2}, \mathrm{n}(\%)$ & $33(63.5)$ & $16(51.6)$ & $17(81 \%)$ & 0.04 \\
\hline Waist circumference, $\mathrm{cm}^{\mathrm{a}}$ & $100.8( \pm 14)$ & $98.6( \pm 14)$ & $104( \pm 14)$ & 0.2 \\
\hline Weight, $\mathbf{k g}^{\mathrm{a}}$ & $80( \pm 17.2)$ & $76.3( \pm 17)$ & $85.6( \pm 16)$ & 0.05 \\
\hline Weight loss, $\%^{c}$ & $6.5(0-32)$ & $10.1(5-32)$ & $0(0-4)$ & 0.0001 \\
\hline Fat mass, $\mathbf{k g}^{\mathrm{a}}$ & $20( \pm 9.6)$ & $18.5( \pm 9.8)$ & $22.4( \pm 9.2)$ & 0.17 \\
\hline Total body water, $\mathbf{k g}^{\mathrm{a}}$ & $43.9( \pm 6.6)$ & $42.8( \pm 6.6)$ & $45.7( \pm 6.3)$ & 0.1 \\
\hline $\mathrm{ECW} / \mathrm{ICW}^{\mathrm{a}}$ & $0.76( \pm 0.06)$ & $0.76( \pm 0.05)$ & $0.75( \pm 0.07)$ & 0.4 \\
\hline $\mathrm{BCM}, \mathbf{k g}^{\mathrm{a}}$ & $29.4( \pm 4.9)$ & $28( \pm 4.4)$ & $31.5( \pm 5.1)$ & 0.014 \\
\hline Phase angle $^{a}$ & $5.7( \pm 1.1)$ & $5.4( \pm 1.1)$ & $6.3( \pm 0.9)$ & 0.005 \\
\hline $\mathrm{SMI}, \mathrm{kg} / \mathrm{m}^{2}$ a & $18( \pm 2.53)$ & $17.9( \pm 2.47)$ & $18.3( \pm 2.67)$ & 0.5 \\
\hline $\mathrm{SMI}<14.6 \mathrm{~kg} / \mathrm{m}^{2}, \mathrm{n}(\%)$ & $5(9.6)$ & $3(9.6)$ & $2(9.5)$ & 0.9 \\
\hline \multicolumn{5}{|l|}{ Laboratory parameters } \\
\hline eGFR $\mathrm{mL} / \mathrm{min}^{\mathrm{b}}$ & $96.7(79-107)$ & $89.7(77-109)$ & $103(86-107)$ & 0.09 \\
\hline CRP $\mathrm{mg} / \mathrm{dL}^{\mathrm{b}}$ & $1.1(0.4-4.1)$ & $2(0.6-5.5)$ & $0.6(0.3-1.6)$ & 0.01 \\
\hline CRP > 1 mg/dl, n (\%) & $27(52)$ & $19(61.3)$ & $8(38.1)$ & 0.1 \\
\hline Albumin $\mathbf{g} / \mathrm{L}^{\mathrm{b}}$ & $36.3(33-41)$ & $33.9(29-39)$ & $39(35-41.7)$ & 0.009 \\
\hline Albumin $<35 \mathrm{~g} / \mathrm{L}, \mathrm{n}(\%)$ & $21(40.3)$ & $16(51)$ & $5(23.8)$ & 0.04 \\
\hline $\mathrm{CHE}, \mathrm{U} / \mathrm{L}^{\mathrm{a}}$ & $6253( \pm 1984)$ & $5629( \pm 2072)$ & $7074( \pm 1512)$ & 0.009 \\
\hline $\mathrm{CHE}<5000 \mathrm{U} / \mathrm{L}, \mathrm{n}(\%)$ & $11(21.2)$ & $10(32.3)$ & $1(4.8)$ & 0.02 \\
\hline$A L P, U / L^{b}$ & $81.5(63-102)$ & $84(72-112)$ & $68(60-87)$ & 0.03 \\
\hline GGT, U/L ${ }^{b}$ & $36(28-67)$ & $37(29-79)$ & $31(22-49)$ & 0.09 \\
\hline Hemoglobin $\mathbf{g} / \mathrm{dL}^{\mathrm{b}}$ & $14(12-15)$ & $13(12-14)$ & $14.5(14-15.6)$ & 0.003 \\
\hline Hemoglobin < 12,5 g/dL, n (\%) & $13(25)$ & $11(35.5)$ & $2(9.5)$ & 0.03 \\
\hline Lymphocytes G/L b & $1.5(1.2-1.9)$ & $1.4(1-1.9)$ & $1.6(1.2-2.3)$ & 0.2 \\
\hline
\end{tabular}

Abbreviations: $B I A$ bioimpedance analysis, $B M I$ body mass index, $E C W$ extracellular water, $I C W$ intracellular water, $B C M$ body cell mass, $S M I$ skeletal muscle index, eGFR estimated glomerular filtration rate, CRP C-reactive protein, CHE cholinesterase, ALP alkaline phosphatase, GGT gamma glutamyl transferase amean \pm SD.

${ }^{b}$ median and interquartile range, 25-75th percentile.

${ }^{c}$ median and minimum/maximum values.

*gastrointestinal (GI) cancer included lower GI (2), higher GI (2), pancreato-biliary (4) tumor; hematological tumor included two myeloma and one chronic lymphocytic leukemia; other were one oropharynx, one mesothelioma and one prostate cancer.

and 0.38 vs $0.27 \mathrm{ng} / \mathrm{mL}, p<0.05)$. In contrast, Ocn and PINP levels did not differ between the two groups of patients. Ca levels were consistently elevated in cachectic patients, regardless of bone metastases (median $2.4 \mathrm{vs}$ $2.3 \mathrm{mmol} / \mathrm{L}, p<0.01)$. Interestingly, the proportion of patients with CTX/Ocn ratio above the median was significantly higher in cachectic than cancer control patients $(67.7$ vs $28.6 \%, p<0.01$ and 67.9 vs $18.8 \%$, $p<0.01$ after exclusion of bone metastases). Similarly, more patients in the cachexia group had elevated CTX/ 
Table 2 Markers of bone turnover and bone regulators

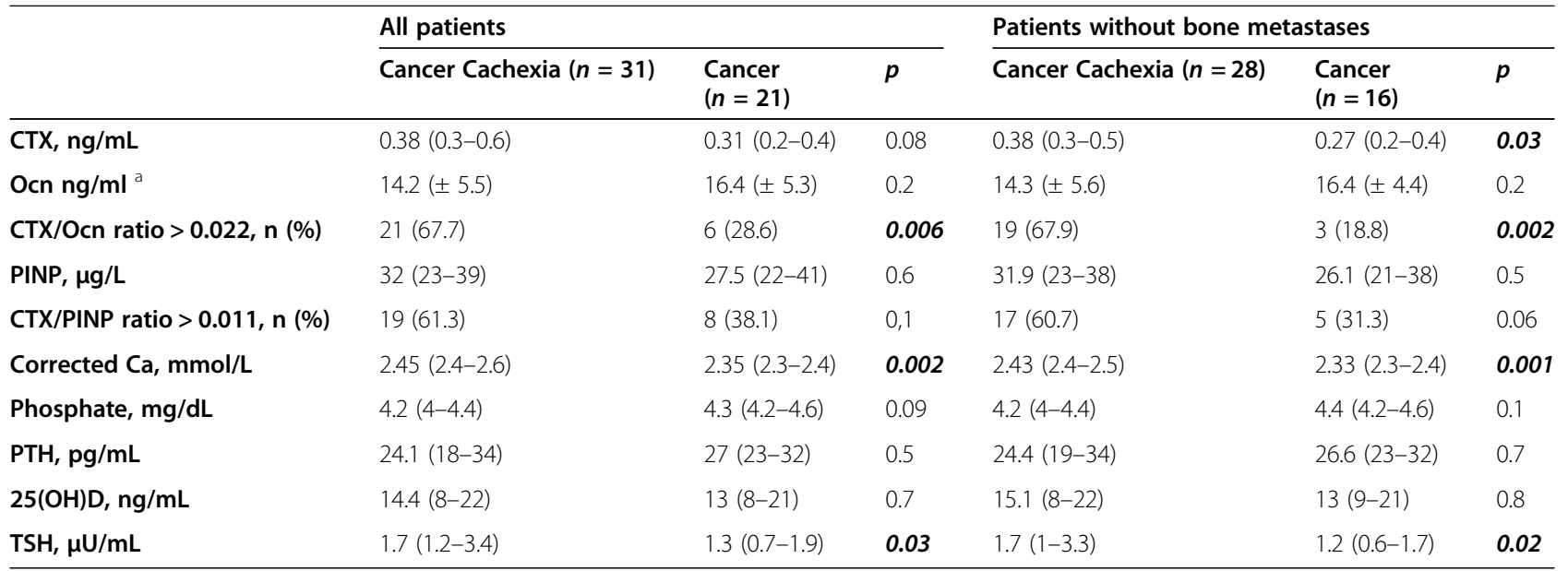

Abbreviations: CTX carboxy terminal telopeptide of collagen type I, Ocn osteocalcin, PINP procollagen type I N-terminal propeptides, 25(OH)D 25-hydroxy vitamin D

- All variables are expressed as median and interquartile range (25-75th percentile), except for Ocn ${ }^{a}(m e a n \pm S D)$

PINP ratio, although the difference did not reach statistical significance $(61.3$ vs $38.1 \%, p=0.1$ in the whole cohort and 60.7 vs. $31.3 \%, p=0.06$ in patients without bone metastases). Importantly, we did not observe any significant difference in BTM levels among tumor types categorized as lung or non-lung cancer or disease stages categorized as I/II, III and IV (suppl. Table 1).

Except for TSH, no difference in bone regulators was observed between the two groups. Of note, in the whole cohort more than $80 \%$ of the patients had a vitamin D deficiency at first diagnosis, independently of cachexia (81\% of cachectic patients vs. $90 \%$ of cancer control, $p=$ 0.3). In addition, two patients (one each in the control and in the cachexia group) had inappropriately high PTH serum levels despite hypercalcemia, suggesting mild hyperparathyroidism.

In summary, the higher CTX serum levels as well as elevated CTX/Ocn and CTX/PINP ratio in cachectic patients compared to controls suggest that cachexia may exacerbate bone turnover in cancer patients.

\section{Association of BTM with body composition and laboratory parameters}

We next evaluated the association of BTMs with body composition and laboratory parameters (Table 3). A correlation analysis revealed that BMI, body weight, waist circumference and total body water were significantly and negatively correlated to CTX $(r=-0.3, p<0.05)$. In contrast, Ocn correlated only to $\mathrm{BCM}(r=0.36, p=$ $0.008)$, as previously reported [27], and PINP to waist circumference $(r=-0.29, p<0,05)$.

Among the laboratory parameters CTX strongly correlated with markers of inflammation, CRP $(r=0.39, p<$ $0.01)$ and albumin $(r=-0.45, p<0.01)$ in particular. In addition, both CTX and Ocn correlated with CHE (CTX $r=-0.39$ and Ocn $r=0.37, p<0.01)$. Regarding bone metabolism parameters, no significant correlation with BTMs was observed. After exclusion of patients with bone metastases, significant correlations persisted between CTX and waist circumference, CRP, albumin, and CHE; Ocn correlated only with BCM; PINP correlated with waist circumference and hemoglobin levels (suppl. Table 2).

Taken together, this data indicates an association between CTX and the clinical and laboratory features characterizing cancer cachexia, such as BMI, albumin, and CRP.

\section{Determinants of negative bone remodeling balance}

The uncoupling of bone formation and resorption results in a negative bone remodeling balance, which is considered a risk factor for osteoporosis and bone fractures [19]. By using the median of our study population as a cutoff (0.022 for CTX/Ocn and 0.011 for CTX/ PINP), BTM ratio $>$ median indicated an unbalanced bone turnover with increased bone resorption $[18,19]$. Among the patients with an elevated CTX/Ocn ratio $78 \%$ were cachectic and $22 \%$ non-cachectic $(p=0.01)$. Similarly, $70.4 \%$ of the patients with increased CTX/ PINP ratio were cachectic (vs. 29.6\% of control, p 0.1). Importantly, after excluding bone metastatic disease the proportion of cachectic and cancer control patients among those with an elevated BTM ratio shifted to $86 \%$ vs. $14 \%$ for the CTX/Ocn ratio $(p=0.004)$ and $77.3 \%$ vs. $22.7 \%$ for the CTX/PINP ratio $(p=0.06)$.

To identify determinants of negative bone remodeling balance in cancer patients, we performed a logistic regression analysis, which revealed hypoalbuminemia for the CTX/Ocn ratio (OR of 19.8, 95\% CI 3.5-111, $p<$ 0.01 ) and high CRP for the CTX/PINP ratio (OR of 5.29, 
Table 3 BTM correlations with anthropometric, BIA and laboratory parameters $(n=52)$

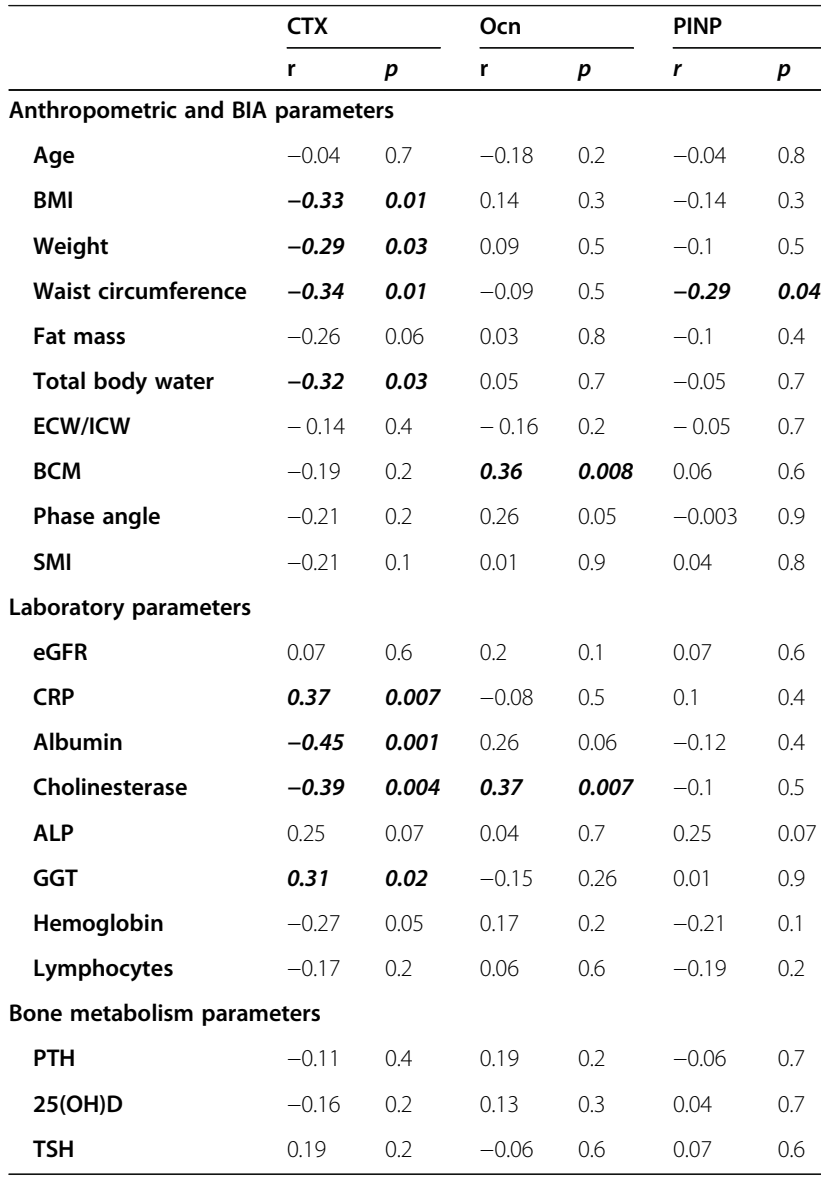

Abbreviations: BTM bone turnover markers, BIA bioimpedance analysis, CTX carboxy terminal telopeptide of collagen type I, Ocn osteocalcin, PINP procollagen type I $\mathrm{N}$-terminal propeptides, $B M I$ body mass index, $E C W$ extracellular water, ICW intracellular water, BCM body cell mass, SMI skeletal muscle index, eGFR estimated glomerular filtration rate, CRP C-reactive protein, ALP alkaline phosphatase, GGT gamma glutamyl transferase, 25(OH)D 25hydroxy vitamin D
95\% CI 1.6-17.5, $p<0.01$ ) as main indicators of unbalanced bone turnover in the whole patient population. After exclusion of patients with bone metastatic disease, both hypoalbuminemia and high CRP were associated with a negative bone turnover (CTX/Ocn: OR 10.5 for hypoalbuminemia and OR 7.6 for high CRP; CTX/PINP: OR 7.7 for high CRP; $p \leq 0.01$ ) (Table 4).

In summary, this data suggests that among the BIA, anthropometric and laboratory parameters, only hypoalbuminemia and high CRP were predictors of the negative bone remodeling balance of cancer patients.

\section{Discussion}

The balance of bone homeostasis can be severely undermined in cancer patients [7]. Several treatment strategies, including chemotherapy and antihormonal agents, lead to bone loss and significantly increase the risk of fracture [28]. Skeletal metastatic disease is also a common cause of deregulated bone metabolism due to pathological cross-talk between tumor cells and the bone milieu [29]. Interestingly, osteopenia and osteoporosis have also been observed in therapy-naïve patients without evidence of skeletal involvement $[8,9]$, thus suggesting that additional factors other than bone metastases and treatments may affect bone turnover in cancer patients. At first diagnosis as many as $42 \%$ of oncological patients present signs of cachexia [30], a multiorgan syndrome characterized by weight loss, wasting of muscle mass and systemic inflammation; all of which are frequently associated with bone loss [31, 32]. However, the effect of cachexia on bone health in cancer patients has not been fully elucidated. In this study, we investigated bone metabolism in treatment-naïve cancer patients and showed for the first time an upregulation of the bone resorption marker, CTX, in the presence of cachexia. In addition, we identified hypoalbuminemia and high CRP

Table 4 Variables associated with a negative bone turnover balance in cancer patients $(n=52)$

\begin{tabular}{|c|c|c|c|c|c|c|}
\hline & \multicolumn{3}{|c|}{ All patients $(n=52)$} & \multicolumn{3}{|c|}{ Patients without bone metastases $(n=44)$} \\
\hline & OR & $\mathrm{Cl}$ & $p$ & OR & $\mathrm{Cl}$ & $p$ \\
\hline \multicolumn{7}{|l|}{$\mathrm{CTX} / \mathrm{Ocn}$ ratio $>0.022^{\mathrm{a}}$} \\
\hline Hypoalbuminemia & 19.8 & $3.5-111.5$ & 0.001 & 10.5 & $1.6-65.6$ & 0.01 \\
\hline High CRP & 4.56 & $1-20$ & 0.05 & 7.6 & $1.5-38.4$ & 0.01 \\
\hline Adjusted R squared & 0.54 & & & 0.52 & & \\
\hline \multicolumn{7}{|l|}{ CTX/PINP ratio $>0.011^{b}$} \\
\hline High CRP & 5.29 & $1.6-17.5$ & 0.006 & 7.7 & $1.9-30.5$ & 0.003 \\
\hline Adjusted R squared & 0.2 & & & 0.3 & & \\
\hline
\end{tabular}

Abbreviations: OR odds ratio, CI confidence interval, CRP C-reactive protein, CTX carboxy terminal telopeptide of collagen type I, Ocn osteocalcin, PINP procollagen type I N-terminal propeptides

- The backward stepwise regression models included:

${ }^{a} \mathrm{BMI}$, body weight loss (weight loss $>0 \%$ ), hypoalbuminemia (albumin $<35 \mathrm{~g} / \mathrm{L}$ ), high CRP (CRP $>1 \mathrm{mg} / \mathrm{dL}$ ), anemia (hemoglobin $<12,5 \mathrm{~g} / \mathrm{dL}$ ), phase angle, eGFR adjusted for age.

body weight loss (weight loss $>0 \%$ ), hypoalbuminemia (albumin $<35 \mathrm{~g} / \mathrm{L}$ ), high CRP (CRP > $1 \mathrm{mg} / \mathrm{dL}$ ), adjusted for age. 
as predictors of the negative bone turnover balance of cancer patients.

Skeletal metabolism is finely tuned by a complex network of local and systemic factors, including gonadal hormones, vitamin $\mathrm{D}$ and $\mathrm{PTH}$, and derangements of these pathways may alter the delicate balance of bone remodeling. Vitamin D deficiency is a frequent finding in cancer patients and may contribute to bone loss due to secondary hyperparathyroidism [33-35]. PTH and tumor-derived PTHrP enhance bone loss by uncoupling bone resorption and formation [36]. Animal studies also suggest that PTHrp may mediate cachexia via browning of adipose tissue and subsequent increase in energy expenditure [37], but the clinical relevance of this pathway has yet to be confirmed. In our study, PTH negatively correlated with Ca levels $(r=-0.39, p<0.01)$, but not with BTMs, thus excluding hyperparathyroidism as a cause of accelerated bone turnover in this patient cohort.

The presence of cachexia has been associated with osteoporosis in patients with chronic obstructive pulmonary disease, rheumatoid arthritis, and heart failure [38, 39]. Indeed, weight loss, muscle wasting, and chronic inflammation alter the balance of bone turnover by increasing bone resorption and inhibiting formation $[31,32,40]$. In our study, BTM ratio was indicative of bone resorption in more than $60 \%$ of the patients with cachexia and the main determinants of the negative bone turnover balance were hypoalbuminemia and high CRP. Importantly, hypoalbuminemia and elevated CRP are not only associated with poor outcomes in several cancer types [21, 41], but also to osteoporosis and fracture risk [42, 43].

The present study has several limitations, including the small number of included patients with different tumor types and disease stages, the absence of a control group with healthy subjects, and the lack of histomorphometric and bone density assessment. Since a negative balance of bone remodeling may lead to low bone mass, a longitudinal design with morphometric correlates and bone imaging studies is warranted to evaluate if increased bone resorption results from hyperactivation of osteoclasts and translates into osteopenia and osteoporosis. Moreover, it is important to point out that the reliability of some BIA measurements is questioned in case of obesity, large tumor mass and fluid retention. In contrast to multi-frequency instruments, single-frequency devices overestimate total body water in case of edema $[44,45]$. In addition, assessment of muscle mass by BIA is inaccurate in obese patients. In our study less than $10 \%$ of the patients was sarcopenic and SMI of cachexia and control patients was similar, despite a significant difference in phase angle. Indeed, in patients with grossly altered body composition, a direct measure of muscularity with computed tomography or dual-energy $\mathrm{X}$-ray is preferred, but not easily available in the clinical routine. The influence of hypogonadism, which is frequently observed in cachectic patients and contributes to accelerated bone remodeling in the elderly, should also be evaluated in follow-up studies [46]. Despite limitations, our data indicates profound changes in bone metabolism due to cachexia in cancer patients. Interestingly, ongoing research is focusing on the effect of bone targeted drugs to alleviate symptoms of cachexia, such as muscle wasting [47-49].

\section{Conclusions}

In conclusion, our study provides evidence for a negative bone remodeling balance in cancer cachexia and supports further research not only to assess the risk of osteoporosis and fracture in this fragile patient population, but also to prevent bone loss and perhaps overcome cachexia-induced muscle wasting using bone modifying agents.

\section{Abbreviations}

25(OH)D: 25-hydroxy vitamin D; ALP: Alkaline phosphatase; BCM: Body cell mass; BIA: Bioimpedance analysis; BMI: Body mass index; BTMs: Bone turnover markers; Ca: Calcium; CHE: Cholinesterase; CRP: C-reactive protein; CTX: Carboxy terminal telopeptide of collagens; ECW: Extracellular water; eGFR: Estimated glomerular filtration rate; GGT: Gamma glutamyl transferase; ICW: Intracellular water; PINP: Procollagen type I N-terminal propeptide; PTH: Parathyroid hormone; PTHrP: Parathyroid hormone related protein; Ocn: Osteocalcin; SD: Standard deviation; SOPs: Standard operating procedures; TSH: Thyroid stimulating hormone

\section{Supplementary Information}

The online version contains supplementary material available at https://doi. org/10.1186/s12885-021-08518-9.

Additional file 1.

\section{Acknowledgements}

The authors want to appreciate the contribution of NÖ Landesgesundheitsagentur, legal entity of University Hospitals in Lower Austria, for providing the organizational framework to conduct this research. They also would like to acknowledge support by Open Access Publishing Fund of Karl Landsteiner University of Health Sciences, Krems, Austria.

\section{Authors' contributions}

$\mathrm{HZ}$ designed the study and analyzed the data; EZT and KH collected data; $\mathrm{AH}$ and JS performed experiments; MP supervised and obtained research funding for the study; SV analyzed and interpreted the data, wrote the manuscript with editing from KP, MW and NJ. All authors read and approved the final manuscript.

\section{Funding}

This work was supported by the Lower Austria Research Promotion Agency (Gesellschaft fuer Forschungsfoerderung Niederoesterreich) (grant number LSC14-021). The funders had no role in the study design, data collection and analysis, decision to publish or preparation of the manuscript.

Availability of data and materials

To preserve patient confidentiality the datasets generated for this study are not publicly available, but will be provided by the corresponding author on reasonable request. 


\section{Declarations}

\section{Ethics approval and consent to participate}

The study was approved by the Ethical Committee of Lower Austria (NÖ Ethikkommission, GS1-EK-4/290-2014) and performed according to the Declaration of Helsinki (1996). All patients provided written informed consent.

\section{Consent for publication}

Not applicable.

\section{Competing interests}

KP has received speaker's honoraria from Celgene, Amgen Inc. and Janssen Pharmaceuticals, consultancy fees from Celgene, Takeda, Janssen Pharmaceuticals and Amgen, and research support from Roche Pharmaceuticals

SV has received speaker's honoraria from Bristol Myers Squibb, Pfizer, MSD, Merck; consultancy fees from Roche, MSD, EUSA Pharma, Merck and travel support from Pfizer, Roche, Pierre Fabre, Angelini.

The other authors declare that there are no conflicts of interest.

\section{Author details}

'Karl Landsteiner University of Health Sciences, Dr. Karl-Dorrek-Strasse 30, Krems 3500, Austria. ${ }^{2}$ Department of Internal Medicine 2, University Hospital Krems, Mitterweg 10, Krems 3500, Austria. ${ }^{3}$ Central Laboratory, Klinikum Wels-Grieskirchen, Grieskirchner Straße 42, Wels 4600, Austria. ${ }^{4}$ Department of Pneumology, University Hospital Krems, Mitterweg 10, Krems 3500, Austria. IMC University of Applied Sciences Krems, Institute Krems Bioanalytics, Magnesitstraße 1, Krems 3500, Austria.

Received: 20 April 2021 Accepted: 11 June 2021

Published online: 28 June 2021

\section{References}

1. von Haehling S, Anker MS, Anker SD. Prevalence and clinical impact of cachexia in chronic illness in Europe, USA, and Japan: facts and numbers update 2016. J Cachexia Sarcopenia Muscle. 2016:7(5):507-9. https://doi. org/10.1002/jcsm.12167.

2. Argiles JM, Stemmler B, Lopez-Soriano FJ, Busquets S. Inter-tissue communication in cancer cachexia. Nat Rev Endocrinol. 2018;15(1):9-20. https://doi.org/10.1038/s41574-018-0123-0.

3. Raggatt $\mathrm{L}$, Partridge NC. Cellular and molecular mechanisms of bone remodeling. J Biol Chem. 2010;285(33):25103-8. https://doi.org/10.1074/jbc R109.041087.

4. Seibel MJ. Biochemical markers of bone turnover: part I: biochemistry and variability. Clin Biochem Rev. 2005;26(4):97-122.

5. Massera D, Xu S, Walker MD, Valderrabano RJ, Mukamal KJ, Ix JH, et al. Biochemical markers of bone turnover and risk of incident hip fracture in older women: the cardiovascular health study. Osteoporos Int. 2019;30(9): 1755-65. https://doi.org/10.1007/s00198-019-05043-1.

6. Civitelli R, Armamento-Villareal R, Napoli N. Bone turnover markers: understanding their value in clinical trials and clinical practice. Osteoporos Int. 2009;20(6):843-51. https://doi.org/10.1007/s00198-009-0838-9.

7. Coleman R, Body JJ, Aapro M, Hadji P, Herrstedt J, Group EGW. Bone health in cancer patients: ESMO Clinical Practice Guidelines. Ann Oncol. 2014; 25(Suppl 3):iii124-37.

8. Dumanskiy W, Syniachenko OV, Stepko PA, Taktashov GS, Chernyshova OY, Stoliarova OY. The state of bone metabolism in lung cancer patients. Exp Oncol. 2018;40(2):136-9. https://doi.org/10.31768/2312-8852.2018.40(2):13 6-139.

9. Lassemillante AC, Doi SA, Hooper JD, Prins JB, Wright OR. Prevalence of osteoporosis in prostate cancer survivors II: a meta-analysis of men not on androgen deprivation therapy. Endocrine. 2015;50(2):344-54. https://doi. org/10.1007/s12020-015-0536-7.

10. El Maghraoui A, Ebo'o FB, Sadni S, Majjad A, Hamza T, Mounach A. Is there a relation between pre-sarcopenia, sarcopenia, cachexia and osteoporosis in patients with ankylosing spondylitis? BMC Musculoskelet Disord. 2016;17(1): 268. https://doi.org/10.1186/s12891-016-1155-z.

11. Choi E, Carruthers K, Zhang L, Thomas N, Battaglino RA, Morse LR, et al. Concurrent muscle and bone deterioration in a murine model of cance cachexia. Phys Rep. 2013;1(6):e00144. https://doi.org/10.1002/phy2.144.
12. Pin F, Barreto R, Kitase Y, Mitra S, Erne CE, Novinger LJ, et al. Growth of ovarian cancer xenografts causes loss of muscle and bone mass: a new model for the study of cancer cachexia. J Cachexia Sarcopenia Muscle. 2018 9(4):685-700. https://doi.org/10.1002/jcsm.12311.

13. Zwickl H, Hackner K, Kofeler H, Krzizek EC, Muqaku B, Pils D, et al. Reduced LDL-cholesterol and reduced Total cholesterol as potential indicators of early Cancer in male treatment-naive Cancer patients with pre-cachexia and Cachexia. Front Oncol. 2020;10:1262. https://doi.org/10.3389/fonc.2020.012 62.

14. Fearon K, Strasser F, Anker SD, Bosaeus I, Bruera E, Fainsinger RL, et al. Definition and classification of cancer cachexia: an international consensus. Lancet Oncol. 2011;12(5):489-95. https://doi.org/10.1016/S1470-2045(1 0)70218-7.

15. Yoon SL, Grundmann O, Williams JJ, Gordan L, George TJ Jr. Body composition changes differ by gender in stomach, colorectal, and biliary cancer patients with cachexia: results from a pilot study. Cancer Med. 2018; 7(8):3695-703. https://doi.org/10.1002/cam4.1665.

16. Grundmann O, Yoon SL, Williams JJ. The value of bioelectrical impedance analysis and phase angle in the evaluation of malnutrition and quality of life in cancer patients--a comprehensive review. Eur J Clin Nutr. 2015;69(12): 1290-7. https://doi.org/10.1038/ejcn.2015.126.

17. Janssen I, Heymsfield SB, Ross R. Low relative skeletal muscle mass (sarcopenia) in older persons is associated with functional impairment and physical disability. J Am Geriatr Soc. 2002;50(5):889-96. https://doi.org/10.1 046/j.1532-5415.2002.50216.x

18. Melton $\sqcup \mathrm{J}$ 3rd, Atkinson EJ, Achenbach SJ, Kanis JA, Therneau TM Johansson $\mathrm{H}$, et al. Potential extensions of the US FRAX algorithm. J Osteoporos. 2012:2012:528790.

19. Fisher A, Fisher L, Srikusalanukul W, Smith PN. Bone turnover status: classification model and clinical implications. Int J Med Sci. 2018:15(4):32338. https://doi.org/10.7150/ijms.22747

20. Holick MF, Binkley NC, Bischoff-Ferrari HA, Gordon CM, Hanley DA, Heaney $R P$, et al. Evaluation, treatment, and prevention of vitamin D deficiency: an Endocrine Society clinical practice quideline. J Clin Endocrinol Metab. 2011: 96(7):1911-30. https://doi.org/10.1210/jc.2011-0385.

21. Forrest LM, McMillan DC, McArdle CS, Angerson WJ, Dunlop DJ. Evaluation of cumulative prognostic scores based on the systemic inflammatory response in patients with inoperable non-small-cell lung cancer. Br J Cancer. 2003;89(6):1028-30. https://doi.org/10.1038/sj.bjc.6601242.

22. D'Andrea D, Soria F, Abufaraj M, Gust K, Foerster B, Vartolomei MD, et al. Clinical value of cholinesterase in the prediction of biochemical recurrence after radical prostatectomy. Urol Oncol. 2018;36(12):528 e527-13.

23. Heymsfield SB, Gonzalez MC, Lu J, Jia G, Zheng J. Skeletal muscle mass and quality: evolution of modern measurement concepts in the context of sarcopenia. Proc Nutr Soc. 2015;74(4):355-66. https://doi.org/10.1017/5002 9665115000129

24. Evans WJ, Morley JE, Argiles J, Bales C, Baracos V, Guttridge D, et al. Cachexia: a new definition. Clin Nutr. 2008;27(6):793-9. https://doi.org/10.1 016/j.clnu.2008.06.013

25. Thibaut MM, Sboarina M, Roumain M, Potgens SA, Neyrinck AM, Destree F, et al. Inflammation-induced cholestasis in cancer cachexia. J Cachexia Sarcopenia Muscle. 2021;12(1):70-90. https://doi.org/10.1002/jcsm.12652.

26. Schwarz S, Prokopchuk O, Esefeld K, Groschel S, Bachmann J, Lorenzen S, et al. The clinical picture of cachexia: a mosaic of different parameters (experience of 503 patients). BMC Cancer. 2017;17(1):130. https://doi.org/1 $0.1186 / 512885-017-3116-9$

27. Liu JM, Zhao HY, Zhao L, Chen Y, Zhang LZ, Tao B, et al. An independent positive relationship between the serum total osteocalcin level and fat-free mass in healthy premenopausal women. J Clin Endocrinol Metab. 2013; 98(5):2146-52. https://doi.org/10.1210/jc.2013-1112.

28. Taxel P, Faircloth E, Idrees S, Van Poznak C. Cancer treatment-induced bone loss in women with breast Cancer and men with prostate Cancer. J Endocr Soc. 2018;2(7):574-88. https://doi.org/10.1210/js.2018-00052

29. Vallet S, Smith MR, Raje N. Novel bone-targeted strategies in oncology. Clin Cancer Res. 2010;16(16):4084-93. https://doi.org/10.1158/1078-0432.CCR-100600

30. De Waele E, Demol J, Caccialanza R, Cotogni P, Spapen H, Malbrain ML, et al. Unidentified cachexia patients in the oncologic setting: Cachexia UFOs do exist. Nutrition. 2019;63-64:200-4. https://doi.org/10.1016/j.nut.2019.02.015.

31. Lopez-Gomez J, Izaola-Jauregui O, Primo-Martin D, Torres-Torres B, GomezHoyos E, Ortola-Buigues A, et al. Effect of weight loss on bone metabolism 
in postmenopausal obese women with osteoarthritis. Obes Res Clin Pract. 2019;13(4):378-84. https://doi.org/10.1016/j.orcp.2019.03.002.

32. Redlich K, Smolen JS. Inflammatory bone loss: pathogenesis and therapeutic intervention. Nat Rev Drug Discov. 2012;11(3):234-50. https://doi.org/10.103 8/nrd3669.

33. Ng K, Sargent DJ, Goldberg RM, Meyerhardt JA, Green EM, Pitot HC, et al. Vitamin D status in patients with stage IV colorectal cancer: findings from intergroup trial N9741. J Clin Oncol. 2011;29(12):1599-606. https://doi.org/1 $0.1200 / \mathrm{JCO} .2010 .31 .7255$

34. Crew KD, Shane E, Cremers S, McMahon DJ, Irani D, Hershman DL. High prevalence of vitamin $D$ deficiency despite supplementation in premenopausal women with breast cancer undergoing adjuvant chemotherapy. J Clin Oncol. 2009;27(13):2151-6. https://doi.org/10.1200/ JCO.2008.19.6162.

35. Lips P, van Schoor NM. The effect of vitamin D on bone and osteoporosis. Best Pract Res Clin Endocrinol Metab. 2011;25(4):585-91. https://doi.org/10.1 016/j.beem.2011.05.002.

36. Stewart AF, Vignery A, Silverglate A, Ravin ND, LiVolsi V, Broadus AE, et al. Quantitative bone histomorphometry in humoral hypercalcemia of malignancy: uncoupling of bone cell activity. J Clin Endocrinol Metab. 1982; 55(2):219-27. https://doi.org/10.1210/jcem-55-2-219.

37. Kir S, White JP, Kleiner S, Kazak L, Cohen P, Baracos VE, et al. Tumourderived PTH-related protein triggers adipose tissue browning and cancer cachexia. Nature. 2014;513(7516):100-4. https://doi.org/10.1038/nature13528.

38. Graat-Verboom L, Spruit MA, van den Borne BE, Smeenk FW, Martens EJ, Lunde $\mathrm{R}$, et al. Correlates of osteoporosis in chronic obstructive pulmonary disease: an underestimated systemic component. Respir Med. 2009;103(8): 1143-51. https://doi.org/10.1016/j.rmed.2009.02.014.

39. Bozic B, Loncar G, Prodanovic N, Radojicic Z, Cvorovic V, Dimkovic S, et al. Relationship between high circulating adiponectin with bone mineral density and bone metabolism in elderly males with chronic heart failure. J Card Fail. 2010;16(4):301-7. https://doi.org/10.1016/j.cardfail.2009.12.015.

40. Tsukamoto M, Mori T, Nakamura E, Okada Y, Fukuda H, Yamanaka Y, et al. Chronic obstructive pulmonary disease severity in middle-aged and older men with osteoporosis associates with decreased bone formation. Osteoporos Sarcopenia. 2020;6(4):179-84. https://doi.org/10.1016/.jafos.202 0.11.003.

41. Demirelli B, Babacan NA, Ercelep O, Ozturk MA, Kaya S, Tanrikulu E, et al. Modified Glasgow prognostic score, prognostic nutritional index and ECOG performance score predicts survival better than sarcopenia, Cachexia and some inflammatory indices in metastatic gastric Cancer. Nutr Cancer. 2021; 73(2):230-8. https://doi.org/10.1080/01635581.2020.1749290.

42. Afshinnia F, Wong KK, Sundaram B, Ackermann RJ, Pennathur S. Hypoalbuminemia and osteoporosis: reappraisal of a controversy. J Clin Endocrinol Metab. 2016;101(1):167-75. https://doi.org/10.1210/jc.2015-3212.

43. Fisher A, Srikusalanukul W, Fisher L, Smith PN. Lower serum P1NP/betaCTX ratio and hypoalbuminemia are independently associated with osteoporotic nonvertebral fractures in older adults. Clin Interv Aging. 2017;12:1131-40. https://doi.org/10.2147/CIA.S141097.

44. Bellafronte NT, Batistuti MR, Dos Santos NZ, Holland H, Romao EA, P GC. Estimation of Body composition and water data depends on the bioelectrical impedance device. J Electr Bioimpedance. 2018;9(1):96-105. https://doi.org/10.2478/joeb-2018-0014.

45. Kyle UG, Bosaeus I, De Lorenzo AD, Deurenberg P, Elia M, Manuel Gomez J, et al. Bioelectrical impedance analysis-part II: utilization in clinical practice. Clin Nutr. 2004;23(6):1430-53. https://doi.org/10.1016/j.Inu.2004.09.012.

46. Khosla S, Melton $\sqcup$ 3rd, Atkinson EJ, O'Fallon WM, Klee GG, Riggs BL. Relationship of serum sex steroid levels and bone turnover markers with bone mineral density in men and women: a key role for bioavailable estrogen. J Clin Endocrinol Metab. 1998;83(7):2266-74. https://doi.org/10.121 0/jcem.83.7.4924.

47. Hain BA, Jude B, Xu H, Smuin DM, Fox EJ, Elfar JC, et al. Zoledronic acid improves muscle function in healthy mice treated with chemotherapy. J Bone Miner Res. 2020;35(2):368-81. https://doi.org/10.1002/jbmr.3890.

48. Essex AL, Pin F, Huot JR, Bonewald LF, Plotkin LI, Bonetto A. Bisphosphonate treatment ameliorates chemotherapy-induced bone and muscle abnormalities in young mice. Front Endocrinol (Lausanne). 2019;10:809. https://doi.org/10.3389/fendo.2019.00809.

49. Bonetto A, Kays JK, Parker VA, Matthews RR, Barreto R, Puppa MJ, et al. Differential bone loss in mouse models of Colon Cancer Cachexia. Front Physiol. 2016;7:679.

\section{Publisher's Note}

Springer Nature remains neutral with regard to jurisdictional claims in published maps and institutional affiliations.

\section{Ready to submit your research? Choose BMC and benefit from:}

- fast, convenient online submission

- thorough peer review by experienced researchers in your field

- rapid publication on acceptance

- support for research data, including large and complex data types

- gold Open Access which fosters wider collaboration and increased citations

- maximum visibility for your research: over $100 \mathrm{M}$ website views per year

At BMC, research is always in progress.

Learn more biomedcentral.com/submissions 